\title{
Increased Circulating Copeptin Levels Are Associated with Vaso-Occlusive Crisis and Right Ventricular Dysfunction in Sickle Cell Anemia
}

\author{
Onur Sinan Devecia Caglar Ozmen ${ }^{a} \quad$ Muhammet Bugra Karaaslan ${ }^{b}$ \\ Aziz Inan Celik ${ }^{a}$ Hatice Rahimova $^{a}$ Anil Akray $^{a} \quad$ Omer Tepe $^{a} \quad$ Emel Gurkan $^{c}$ \\ Ali Deniz ${ }^{a}$
}

aDepartment of Cardiology, Faculty of Medicine, Cukurova University, Adana, Turkey; ${ }^{b}$ Department of Cardiology,

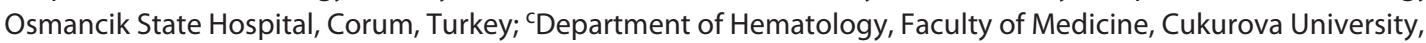
Adana, Turkey

\section{Highlights of the Study}

- Vaso-occlusive crisis (VOC) is a common clinical manifestation of sickle cell anemia (SCA).

- SCA associated right ventricular (RV) dysfunction appears to be an important cause of decreased quality of life and early mortality in these patients.

- Copeptin may be considered for use as a potential biomarker in predicting VOCs in patient with SCA and in the early detection of patients with who have the potential to develop RV dysfunction.

\section{Keywords}

Sickle cell anemia · Vaso-occlusive crisis · Copeptin · Right ventricular dysfunction

\begin{abstract}
Objective: Vaso-occlusive crisis (VOC) is a common clinical manifestation of sickle cell anemia (SCA) and is associated with increased proinflammatory mediators. Copeptin is the C-terminal part of the prohormone for provasopressin and seems clinically relevant in various clinical conditions. Right ventricular (RV) dysfunction significantly appears in SCA patients due to pulmonary hypertension. This study aimed to investigate the association of copeptin levels in VOC patients and evaluate RV dysfunction. Materials and Methods: A total of 108 patients were enrolled in the study. Twentyeight SCA patients in steady state (30.2 \pm 0.9 years), 25 SCA
\end{abstract}

karger@karger.com www.karger.com/mpp

Karger $\stackrel{\text { ' }}{5}$
C 2021 The Author(s).

Published by S. Karger AG, Basel

This is an Open Access article licensed under the Creative Commons Attribution-NonCommercial-4.0 International License (CC BY-NC) (http://www.karger.com/Services/OpenAccessLicense), applicable to the online version of the article only. Usage and distribution for commercial purposes requires written permission. patients in VOC (36.8 \pm 11.8 years), and 55 healthy individuals (31.9 \pm 9.4 years) with HbAA genotype were included. Clinical, echocardiographic, and laboratory data were recorded. ELISA was used for the determination of serum levels of copeptin. Results: VOC patients had significantly higher copeptin level compared both with controls and SCA subjects in steady state $(22.6 \pm 13.0$ vs. $11.3 \pm 5.7 \mathrm{pmol} / \mathrm{L}, 22.6 \pm$ 13.0 vs. $12.4 \pm 5.8 \mathrm{pmol} / \mathrm{L}, p=0.009$ for both). Additionally, the copeptin level was significantly higher in SCA patients with RV dysfunction than those without RV dysfunction (23.2 \pm 12.2 vs. $15.3 \pm 9.5 \mathrm{pmol} / \mathrm{L}, p=0.024$ ). Multiple logistic regression analysis revealed that high-sensitivity C-reactive protein and copeptin levels were found to be associated with VOC. Conclusion: This study showed that copeptin and hs-CRP levels were increased in patients with VOC, and it was found that RV dysfunction was more common in SCA patients with VOC than in the control group. Copeptin can be 
considered for use as a potential biomarker in predicting VOC crisis in SCA patients and in the early detection of patients with SCA who have the potential to develop RV dysfunction.

(C) 2021 The Author(s).

Published by S. Karger AG, Basel

\section{Introduction}

Sickle cell anemia (SCA) is one of the most common hereditary diseases in the world. The substitution of amino acid valine for glutamic acid at the sixth position of beta chain of hemoglobin is the cause of the genetic abnormality. HbS polymerizes due to deoxygenation and causes sickling in erythrocytes, leading to clinical manifestations of SCA including recurrent vaso-occlusive crisis (VOC) which leads to microvascular obstruction, anemia, and decreased red cell survival $[1,2]$. The pathophysiology of VOC includes the activation of endothelial and coagulation factors, acute aggravation of ongoing inflammation with neutrophils and other inflammatory cells, and increased oxidative stress. The activation of inflammatory cells and their signaling pathways leads to the production and secretion of numerous molecules that propagate the inflammatory state in SCD [3]. Even in sickle cell patients without VOC, a chronic inflammatory state is present as reflected by increased levels of circulating CRP, inflammatory cytokines, increased levels of von Willebrand factor antigen, and activated neutrophils, indicating chronic endothelial activation [4].

The need for faster diagnosis, more accurate prognostic assessment, and treatment decisions in various diseases has led to the investigations of new biomarkers. Arginine vasopressin (AVP) is a multifunctional nanopeptide with endocrine, hemodynamic, and osmoregulatory effects, also known as antidiuretic hormone [5]. AVP is a primary hypothalamic stress hormone stimulated by stress factors such as hypotensive, hypoxic, hyperosmolar, hypovolemic, and acidic stimuli [6]. Due to its short half-life and instability in circulation, the measurement of AVP as a biomarker in daily clinical practice is limited. Copeptin, a peptide consisting of 39 amino acids, is a fragment of preprovasopressin that is synthesized and secreted in equimolar amounts to vasopressin. Unlike AVP, copeptin is stable for a long time in plasma and can be measured easily $[7,8]$. It is secreted in a pulsatile manner and is removed from circulation by binding to platelets [9].

Sickle cell anemia-associated right ventricular (RV) dysfunction appears to be an important cause of de- creased quality of life and early mortality in these patients $[10,11]$. Increased RV systolic pressure, RV dilatation and/or dysfunction, tricuspid regurgitation (TR), right atrial dilatation, and flattening in the interventricular septum are findings of pulmonary hypertension. In SCA, chronic hemolytic and VOC may result in obstructive pulmonary vasculopathy and consequently RV dysfunction.

Akinlade et al. $[12,13]$ published 2 studies on the relationship between SCA and serum copeptin levels. In the first of these studies, the relationship between the severity of SCA and copeptin level, and in the second, the copeptin levels of the patients in steady state and VOC crisis were compared with the control group $[12,13]$. The authors reported that copeptin levels of moderate and severe SCA patients were higher than copeptin levels of mild SCA patients [12]. In their second study, Akinlade et al. [13] found that copeptin levels of SCA patients were lower than those in the control group, while copeptin levels of the VOC group were found to be higher than those in the steady state SCA patients. This study was designed to determine the association of copeptin levels and RV dysfunction in SCA with and without VOC

\section{Materials and Methods}

\section{Study Population}

A total of 108 participants were recruited from Departments of Hematology and Cardiology, Cukurova University Hospital, Adana, Turkey. Twenty-eight SCA patients in steady state, 25 SCA patients in VOC, and 55 apparently healthy individuals with HbAA genotype were included in the study. Patients with SCA were diagnosed with $\mathrm{HB}$ electrophoresis.

Subjects with bone and joint pain or pain in multiple sites, requirement for analgesics, and patients considering the episode as typical of crisis which necessitates hospital admission were clinically considered as being in VOC [14]. Hospitalization was an inclusion criterion for VOC. Steady-state subjects were those with no acute complicating factors or acute clinical symptoms or crisis for at least 3 months [13]. This was established by a careful history and complete physical examination. Subjects with $\mathrm{Hb}$ variants different from HbSS (such as HbSC and HbAS), acute major stresses other than VOC, blood transfusion within the previous 2 months, end-stage renal failure $\left(\mathrm{GFR}<15 \mathrm{~mL} / \mathrm{min} / 1.73 \mathrm{~m}^{2}\right.$ or renal replacement treatment), diabetes mellitus, hypertension, hepatitis, and cancer and with established endocrine dysfunctions were excluded from this study. Pregnant and lactating mothers were also excluded from the study. Patients were considered as having VOC for the duration of their pain symptoms, and no time-limit exclusion criteria were set in this regard.

Clinical and Echocardiographic Evaluation

Demographic and clinical data of the patients were obtained. Echocardiographic examination was performed using the Vivid S5
Deveci/Ozmen/Karaaslan/Celik/ Rahimova/Akray/Tepe/Gurkan/Deniz 
cardiovascular ultrasound system with a $3 \mathrm{~S} 1.5-3.6 \mathrm{MHz}$ transthoracic probe (GE Medical Systems, Buckinghamshire, UK). Each echocardiographic measurement was performed 3 times by a cardiologist blinded to the specific clinical history of the patient and then averaged. Left ventricular end-diastolic diameter, ejection fraction, and right atrium diameters were measured according to recommendations by The American Society of Echocardiography [15]. The tricuspid annular plane systolic excursion (TAPSE) was measured as the distance of systolic movement of the RV tricuspid annular segment along its longitudinal plane. RV dimensions were measured from an RV-focused apical 4-chamber view. Doppler echocardiography was used prospectively to estimate systolic pulmonary artery pressure through measurement of the TR velocity. RV fractional area change was calculated from the apical 4-chamber view using the percentage change in areas of the end-diastolic and end-systolic areas of the RV. Specifically, RV function was evaluated for the presence or absence of the following signs: RV diameter $>35 \mathrm{~mm}$ or RV/LV end-diastolic ratio $>1$ from the apical 4 -chamber view; and TAPSE $<15 \mathrm{~mm}$. A diagnosis of RV dysfunction was established in the presence of 2 or more of these criteria.

\section{Laboratory Evaluation}

Samples were procured either during VOC or at steady state. In patients with a diagnosis of VOC, blood samples were taken for copeptin immediately after hospital admission. No intervention (blood transfusion or hydroxyurea) was made prior to blood sample collection for copeptin. After a fasting period of at least $12 \mathrm{~h}$, blood samples were drawn to examine high-sensitivity C-reactive protein (hs-CRP), sedimentation, and renal function parameters. Serum copeptin level was analyzed with a novel, commercially available immunoluminometric assay (BRAHMS LUMItest CTproAVP; Brahms AG, Hennigsdorf/Berlin, Germany) as described previously [9]. The analytical detection limit was $1.7 \mathrm{pmol} / \mathrm{L}$, and inter-laboratory CVs for values of $>2.25 \mathrm{pmol} / \mathrm{L}$ were $<20 \%$, and $10 \%$ for values of $9 \mathrm{pmol} / \mathrm{L}$.

\section{Statistical Analysis}

All analyses were performed using IBM SPSS Statistics Version 20.0 statistical software package. Categorical variables were expressed as numbers and percentages, whereas continuous variables were summarized as mean and standard deviation and as median and minimum-maximum where appropriate. $\chi^{2}$ test was utilized to consider categorical variables between the groups. For comparison of continuous variables between 2 groups, Student's $t$ test or the Mann-Whitney U test was applied depending on whether the statistical hypotheses were fulfilled or not. For non-normally distributed data, the Kruskal-Wallis test was performed to measure the difference between more than 2 groups. Bonferroni-adjusted Mann-Whitney U test was applied for multiple comparisons of groups. To evaluate the correlations between measurements, Pearson correlation coefficient was used. Logistic regression analysis was used to identify notable indicators of VOC in all SCA patients (steady state vs. VOC). Age, RV dysfunction, creatinine, hs$\mathrm{CRP}$, and copeptin were entered as predictor variables into our logistic regression analysis. A receiver operator characteristics (ROC) curve analysis was used to determine the optimal cutoff point of the copeptin and hs-CRP, and IU method to identify the optimal cutoff point. We compared the area under curves (AUCs) with use of the DeLong test. The statistical level of significance for all tests was considered to be 0.05 .

Copeptin Levels in Sickle Cell Anemia

\section{Results}

In our study, no significant difference was found in terms of age in the control group (31.9 \pm 9.4 years), steadystate SCA patients (30.2 \pm 10.9 years), and SCA patients with VOC ( $36.8 \pm 11.8$ years $)(p=0.77)$. The mean hematocrit level and systolic blood pressure were significantly higher in controls compared with SCA subjects in steady state. The mean hematocrit level and systolic blood pressure were significantly higher in SCA subjects in VOC compared with SCA subjects in steady state. It was observed that SCA subjects in VOC had significantly higher mean heart rate compared with controls and SCA subjects in steady state. The mean levels of erythrocyte sedimentation rate, creatinine, white blood cell, and highsensitive C-reactive protein (hs-CRP) were significantly higher in SCA subjects in steady state compared with controls. It was observed that SCA subjects in VOC had significantly higher mean level of erythrocyte sedimentation rate, creatinine, white blood cell, and hs-CRP compared with controls (Table 1). Fifty-seven percent of all SCA patients ( $68 \%$ of the steady state patients and $44 \%$ of VOC patients) were on hydroxyurea therapy. When all SCA patients were evaluated, it was found that hydroxyurea therapy had no significant effect on mean copeptin level (patients on hydroxyurea therapy $16.7 \pm 5.6 \mathrm{pmol} / \mathrm{L}$ vs. no hydroxyurea therapy $18.3 \pm 7.2 \mathrm{pmol} / \mathrm{L}, p=0.131$ ).

It was observed that SCA subjects in VOC had significantly higher mean copeptin level compared both with controls and SCA subjects in steady state ( $22.6 \pm 13.0$ vs. $11.3 \pm 5.7 \mathrm{pmol} / \mathrm{L}, 22.6 \pm 13.0$ vs. $12.4 \pm 5.8 \mathrm{pmol} / \mathrm{L}, p=$ 0.009 for both) Figure 1. RV dysfunction was detected in 13 patients in all SCA patients ( 5 in steady state, 8 in VOC group). Furthermore, the copeptin level was found to be significantly higher in SCA patients with RV dysfunction compared with those without RV dysfunction (23.2 \pm 12.2 vs. $15.3 \pm 9.5 \mathrm{pmol} / \mathrm{L}, p=0.024$ ) Figure 1 .

Right ventricular end-diastolic diameter, systolic pulmonary artery pressure, and TR flow velocity were significantly higher in SCA subjects in steady state compared with controls. It was also observed that SCA subjects in VOC had significantly higher right ventricular end-diastolic diameter and TR flow velocity compared with controls. RV fractional area change and TAPSE were significantly lower in SCA subjects in steady state compared with controls. Similarly, SCA subjects in VOC had significantly lower RV fractional area change and TAPSE compared with controls (Table 1).

Multiple logistic regression analysis was utilized to identify the factors that were associated with the risk of VOC 
Table 1. Patient characteristics in patients with SCA in steady state, VOC, and controls

\begin{tabular}{|c|c|c|c|c|}
\hline & $\begin{array}{l}\text { Controls } \\
(n=55)\end{array}$ & $\begin{array}{l}\text { Steady state } \\
(n=28)\end{array}$ & $\begin{array}{l}\text { VOC } \\
(n=25)\end{array}$ & $p$ value \\
\hline Age & $31.9 \pm 9.4$ & $30.2 \pm 10.9$ & $36.8 \pm 11.8$ & 0.077 \\
\hline $\mathrm{BMI}, \mathrm{kg} / \mathrm{m}^{2}$ & $25.6 \pm 2.6$ & $26.3 \pm 4.0$ & $26.9 \pm 5.3$ & 0.839 \\
\hline Systolic BPa, c, mm Hg & $125.8 \pm 10.6$ & $123.8 \pm 4.6$ & $131.7 \pm 8.1$ & 0.014 \\
\hline Diastolic BP, $\mathrm{mm} \mathrm{Hg}$ & $74.5 \pm 5.2$ & $72.4 \pm 6.7$ & $74.7 \pm 6.1$ & 0.412 \\
\hline Heart rate ${ }^{b, c}$, bpm & $83.3 \pm 10.0$ & $84.8 \pm 16.5$ & $101.4 \pm 16.1$ & $<0.001$ \\
\hline Left ventricle ejection fraction, $\%$ & $64.8 \pm 3.4$ & $63.8 \pm 3.8$ & $63.6 \pm 3.5$ & 0.234 \\
\hline $\mathrm{RVDd}^{\mathrm{a}, \mathrm{b}}$ & $27.6 \pm 4.3$ & $38.5 \pm 8.1$ & $41.9 \pm 7.0$ & $<0.001$ \\
\hline TAPSE $^{\mathrm{a}, \mathrm{b}}, \mathrm{mm}$ & $23.7 \pm 2.5$ & $20.8 \pm 4.0$ & $17.2 \pm 5.7$ & $<0.001$ \\
\hline RV fractional area change $\mathrm{e}^{\mathrm{a}, \mathrm{b}}, \%$ & $47.2 \pm 8.3$ & $32.4 \pm 4.4$ & $28.9 \pm 7.2$ & $<0.001$ \\
\hline LVDd, mm & $48.5 \pm 5.6$ & $49.9 \pm 3.2$ & $50.1 \pm 4.5$ & 0.083 \\
\hline sPAPa & $26.1 \pm 5.9$ & $28.8 \pm 8.9$ & $31.2 \pm 6.8$ & 0.020 \\
\hline RA minor axis, mm & $32.3 \pm 3.4$ & $31.8 \pm 4.9$ & $34.1 \pm 6.8$ & 0.384 \\
\hline TR velocity ${ }^{a}, \mathrm{~b}, \mathrm{~m} / \mathrm{s}$ & $2.5 \pm 2.5$ & $2.7 \pm 0.5$ & $2.9 \pm 0.6$ & $<0.001$ \\
\hline Hematocrit ${ }^{a}, c, \%$ & $39.0 \pm 3.5$ & $35.7 \pm 2.8$ & $38.2 \pm 2.3$ & $<0.001$ \\
\hline $\mathrm{ESR}^{\mathrm{a}, \mathrm{b}}$ & $6.8 \pm 3.2$ & $21.8 \pm 8.1$ & $35.4 \pm 10.9$ & $<0.001$ \\
\hline Creatinine $^{a, b}, \mathrm{mg} / \mathrm{dL}$ & $0.7 \pm 0.2$ & $0.9 \pm 0.1$ & $1.2 \pm 1.8$ & $<0.001$ \\
\hline $\mathrm{WBC}^{\mathrm{a}}, \mathrm{b}, 10^{3} / \mu \mathrm{L}$ & $9.4 \pm 2.2$ & $11.7 \pm 3.4$ & $14.0 \pm 4.0$ & $<0.001$ \\
\hline $\mathrm{hs}-\mathrm{CRP}^{\mathrm{a}}, \mathrm{b}, \mathrm{mg} / \mathrm{dL}$ & $2.1 \pm 1.1$ & $16.2 \pm 11.2$ & $32.7 \pm 21.5$ & $<0.001$ \\
\hline Copeptin ${ }^{\mathrm{b}, \mathrm{c}}, \mathrm{pmol} / \mathrm{L}$ & $11.3 \pm 5.7$ & $12.4 \pm 5.8$ & $22.6 \pm 13.0$ & 0.009 \\
\hline
\end{tabular}

(Table 2). The results indicated that hs-CRP and copeptin were significantly associated with VOC. In this model, higher hs-CRP (OR 1.07, 95\% CI: 1.02-1.12, $p=0.007$ ) and copeptin (OR 1.09, 95\% CI: 1.01-1.19, $p=0.033$ ) levels were associated with VOC. The prognostic value of copeptin for predicting VOC in SCA subjects is presented with the ROC curves in Figure 2. With regard to SCA patients who presented with VOC and those who were in stable condition, the AUC for copeptin was 0.666 (95\% CI, 0.516-0.816). Defining a copeptin threshold of $13.8 \mathrm{pmol} / \mathrm{L}$ at baseline, the sensitivity and specificity for this cutoff were 64.0 and $60.0 \%$, respectively $(p=0.039$ ). Defining an hs-CRP threshold of $17.0 \mathrm{mg} / \mathrm{L}$ at baseline, the sensitivity and specificity for this cutoff were 76.0 and $60.0 \%$, respectively $(p=0.024)$. Statistically significant AUC differences were not found between the copeptin and hs-CRP $(p=0.562)$.

\section{Discussion}

The primary outcome of our study is that the patients with VOC have significantly higher copeptin levels than those in steady state and healthy controls. The cutoff val- ue of copeptin $\geq 13.8 \mathrm{pmol} / \mathrm{L}$ (with sensitivity and specificity were 64.0 and $60.0 \%$, respectively) is related to VOC risk.

Vasopressin is an antidiuretic and vasoconstrictive hormone. Copeptin is a fragment of preprovasopressin that is synthesized and secreted in equimolar amounts to vasopressin from the neurohypophysis and is more stable, hence it overcomes the limitations and difficulties of measuring vasopressin [9]. Copeptin is released into the circulation in cases of hemodynamic stress. Among these are acute coronary syndrome [16], heart failure [17], pulmonary hypertension [18], sepsis [19], and acute pulmonary embolism [20]. In addition, copeptin levels in the blood rise rapidly also when the inflammatory process develops. The exact mechanism of the VOC has not been clarified fully yet. Some reports have shown that the inflammatory process that occurs in response to an impaired hemodynamic state plays an important role in the development of VOC [21]. Akinlade et al. [13] compared copeptin levels between VOC and steady state SCA patients and controls and found that copeptin levels of SCA patients were lower than those in the control group, while copeptin levels of the VOC group were found to be high-
50

Med Princ Pract 2022;31:47-53

DOI: $10.1159 / 000521216$
Deveci/Ozmen/Karaaslan/Celik/ Rahimova/Akray/Tepe/Gurkan/Deniz 


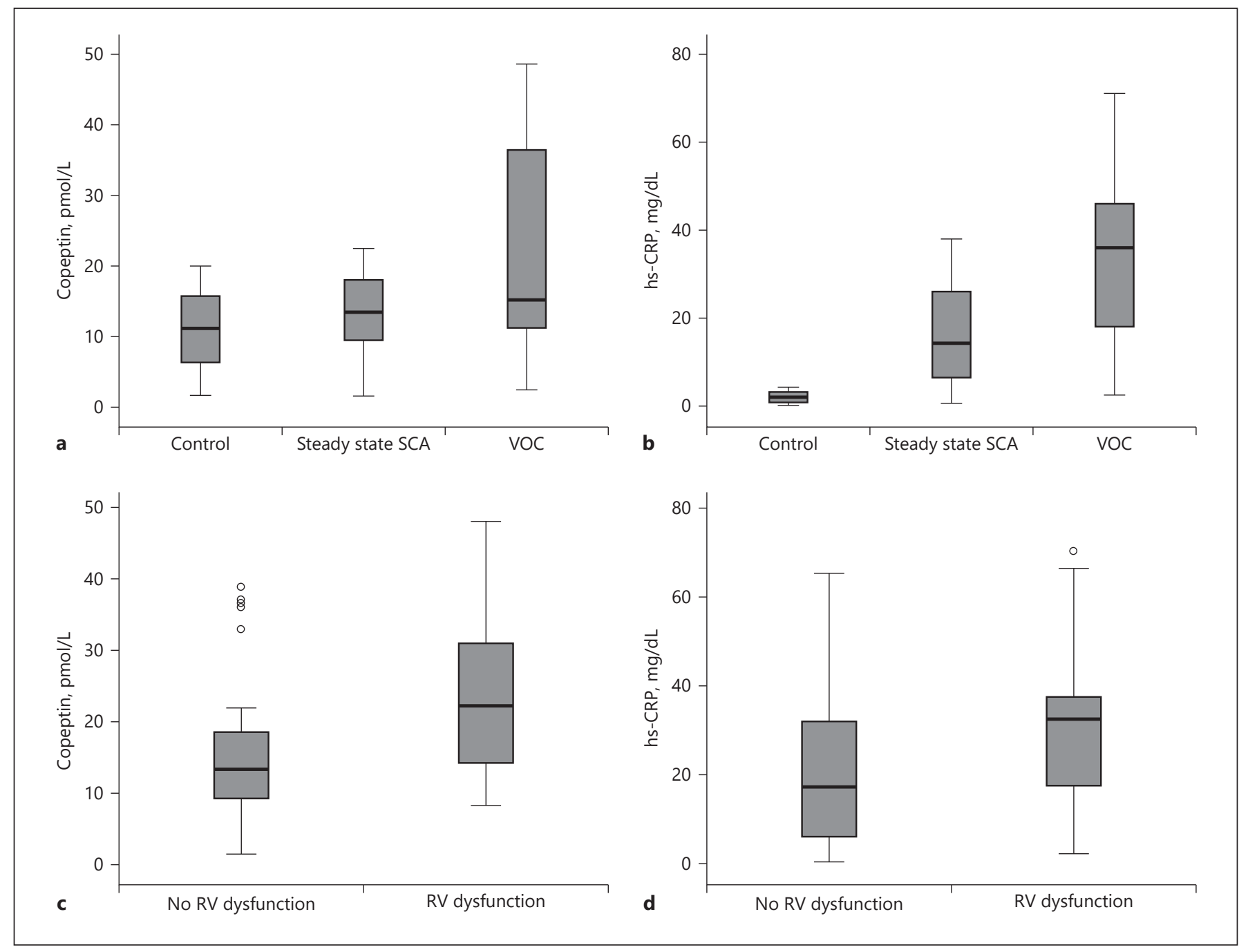

Fig. 1. Distribution of copeptin (a) and hs-CRP (b) in the control, steady-state SCA, and VOC patients. Distribution of copeptin (c) and hs-CRP (d) in the SCA patients with or without RV dysfunction.

er than those in the steady state SCA patients. Another study by Akinlade et al. [12] reported that copeptin levels of moderate and severe SCA patients were higher than copeptin levels of mild SCA patients. There is a similarity and a difference between the results of the first study by Akinlade et al. [12] and our study. Unlike Akinlade et al. [12], copeptin levels of both groups with SCA were found to be significantly higher than those of the control group in our study. The similar result is that the copeptin levels of patients presenting with VOC were found to be higher than those of steady state patients.

In our study, we found a significant relationship between VOC and hs-CRP, and an increased hs-CRP level reflects acute inflammatory response during VOC.
Table 2. Modeling association of parameters for the VOC

\begin{tabular}{lll}
\hline & Odds ratio $(95 \% \mathrm{Cl})$ & $p$ value \\
\hline Age (years) & $1.05(0.99-1.11)$ & 0.108 \\
RV dysfunction & $0.73(0.12-4.36)$ & 0.729 \\
Creatinine $(\mathrm{mg} / \mathrm{dL})$ & $1.18(0.35-4.02)$ & 0.787 \\
hs-CRP $(\mathrm{mg} / \mathrm{L})$ & $1.07(1.02-1.12)$ & $\mathbf{0 . 0 0 7}$ \\
Copeptin $(\mathrm{pmol} / \mathrm{L})$ & $1.09(1.01-1.19)$ & $\mathbf{0 . 0 3 3}$
\end{tabular}

Bold values indicate statistical significance $(p<0.05)$. 


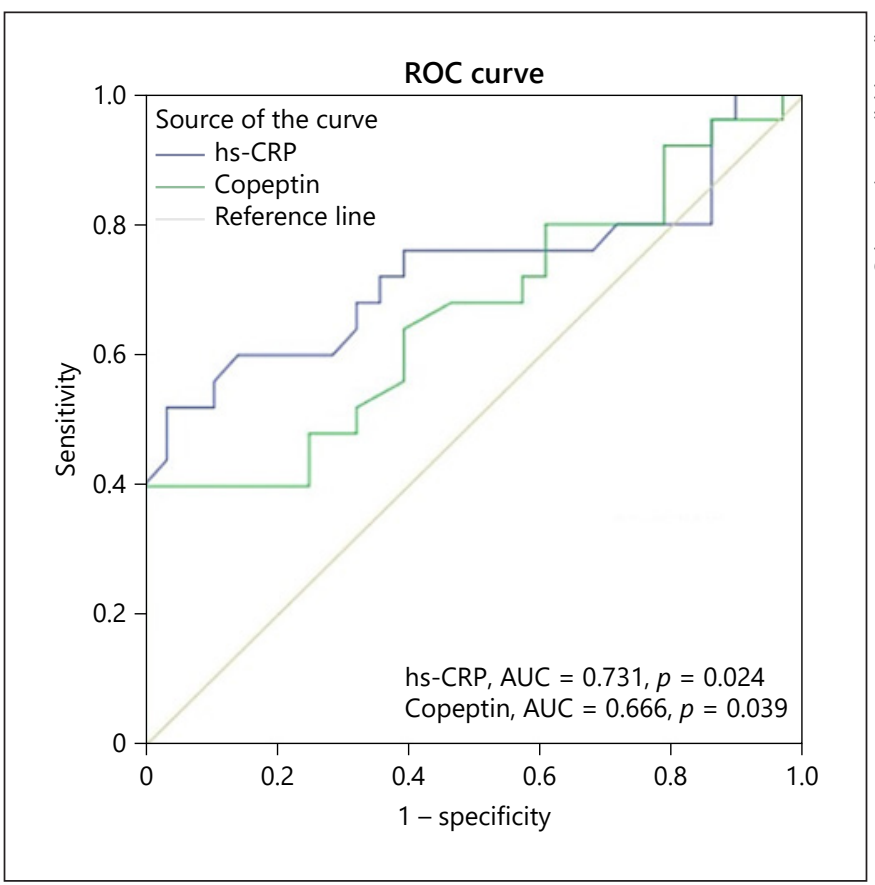

Fig. 2. ROC curve analysis of hs-CRP and copeptin levels for predicting VOC in SCA.

Increased proinflammatory cytokine production is reported in individuals with SCA who develop VOC [22, 23 ]. Studies have shown that increased inflammation and oxidative damage in the cell membrane by intracellular hemoglobin polymerization may be associated with increased CRP levels [24, 25]. High sensitive CRP level was found to be higher in patients with VOC compared with other 2 groups. It was observed that both copeptin and hs-CRP performed well in evaluating VOC risk for SCA patients. No difference was found between hs-CRP and copeptin in terms of the area below ROC curve.

Another finding of the present study revealed a significantly higher dysfunction of the RV in SCA patients in VOC crisis compared with healthy subjects. In addition, the copeptin level was found to be significantly higher in SCA patients who developed RV dysfunction compared with those who did not. Previous studies with adults with SCA showed that recurring VOC for many years led to progressively worsening pulmonary vascular obstructive disease and consequently to RV dysfunction [26-28]. Vasopressin plays a role in cardiac remodeling by the way of V1 receptor on cardiomyocytes and leads to increased protein synthesis, cardiac hypertrophy, decreased contractility, and develop- ment of myocardial fibrosis [29]. Even though these observations are mostly derived from the left ventricle, they increase the likelihood that increased vasopressin levels in SCA patients may play a role in RV remodeling. Taken together, these data suggest that activation of the AVP system measured by copeptin levels may be associated with neurohumoral stimulation in SCA patients who develop RV dysfunction. As RV dysfunction is known to be a poor prognostic factor in patients with SCA, it would be worthwhile to evaluate copeptin levels in patients with SCA.

This study has several limitations. An important limitation was that it was a single-center study involving a relatively small number of patients. Therefore, the results of this study should be supported by multicenter studies involving a larger number of patients. Besides, copeptin levels were analyzed only at first admission. Finally, the study design did not allow the evaluation of prognostic significance of copeptin measurement. More comprehensive information on the prognostic value of copeptin can be provided with prospective studies in the future studies.

\section{Conclusion}

In conclusion, this study showed that high levels of copeptin and hs-CRP were associated with VOC risk. We suggest that copeptin can be used as a potential biomarker in predicting VOC crisis in SCA patients and in early detection of patients with SCA who have the potential to develop RV dysfunction.

\section{Statement of Ethics}

The study was approved by the local Ethics Committee of $\mathrm{Cu}$ kurova University (Decision no: [87/61 on April 5, 2019]) and conformed to the Declaration of Helsinki. Written informed consent was obtained from all participants.

\section{Conflict of Interest Statement}

The authors have no conflicts of interest to declare.

\section{Funding Sources}

No funding was obtained for this research.
Deveci/Ozmen/Karaaslan/Celik/ Rahimova/Akray/Tepe/Gurkan/Deniz 


\section{Author Contributions}

O.S. Deveci, A. Deniz, and C. Ozmen contributed to design and supervision of the project, obtaining, analyzing, and interpreting data. M.B. Karaaslan, A.I. Celik, H. Rahimova, A. Akray, and O. Tepe contributed to acquisition and analyses of data. E. Gurkan contributed to revision of manuscript.

\section{Data Availability Statement}

The data that support the findings of this study are not publicly available due to their containing information that could compromise the privacy of research participants but are available from the corresponding author O.S.D. upon reasonable request.

\section{References}

1 Platt OS, Brambilla DJ, Rosse WF, Milner PF, Castro O, Steinberg MH, et al. Mortality in sickle cell disease. Life expectancy and risk factors for early death. N Engl J Med. 1994; 330(23):1639-44.

2 Taylor JG, Nolan VG, Mendelsohn L, Kato GJ, Gladwin MT, Steinberg MH. Chronic hyper-hemolysis in sickle cell anemia: association of vascular complications and mortality with less frequent vasoocclusive pain. PLoS One. 2008;3(5):e2095.

3 Schimmel M, Luken BM, Nur E, van Tuijn CFJ, Sins JW, Brandjes DPM, et al. Inflammatory and endothelial markers during vaso-occlusive crisis and acute chest syndrome in sickle cell disease. Am J Hematol. 2017; 92(11):E634-6.

4 Hebbel RP, Osarogiagbon R, Kaul D. The endothelial biology of sickle cell disease: inflammation and a chronic vasculopathy. Microcirculation. 2004;11(2): 129-51.

5 Morgenthaler NG, Müller B, Struck J, Bergmann A, Redl H, Christ-Crain M. Copeptin, a stable peptide of the arginine vasopressin precursor, is elevated in hemorrhagic and septic shock. Shock. 2007;28(2):219-26.

6 Stolz D, Christ-Crain M, Morgenthaler NG, Leuppi J, Miedinger D, Bingisser R, et al. Copeptin, C-reactive protein, and procalcitonin as prognostic biomarkers in acute exacerbation of COPD. Chest. 2007;131(4):1058-67.

7 Land H, Schütz G, Schmale H, Richter D. Nucleotide sequence of cloned cDNA encoding bovine arginine vasopressin-neurophysin II precursor. Nature. 1982;295(5847):299-303.

8 Holwerda DA. A glycopeptide from the posterior lobe of pig pituitaries. I. Isolation and characterization. Eur J Biochem. 1972;28(3): 334-9.

9 Morgenthaler NG, Struck J, Alonso C, Bergmann A. Assay for the measurement of copeptin, a stable peptide derived from the precursor of vasopressin. Clin Chem. 2006;52(1): 112-9.

10 Gladwin MT, Sachdev V, Jison ML, Shizukuda Y, Plehn JF, Minter K, et al. Pulmonary hypertension as a risk factor for death in patients with sickle cell disease. N Engl J Med. 2004; 350(9):886-95.
11 Castro O, Gladwin MT. Pulmonary hypertension in sickle cell disease: mechanisms, diagnosis, and management. Hematol Oncol Clin North Am. 2005;19(5):881-96; vii.

12 Akinlade KS, Atere AD, Rahamon SK, Olaniyi JA. Serum levels of copeptin, C-reactive protein and cortisol in different severity groups of sickle cell anaemia. Niger J Physiol Sci. 2013;28(2):159-64.

13 Akinlade KS, Atere AD, Olaniyi JA, Rahamon SK, Adewale CO. Serum copeptin and cortisol do not accurately predict sickle cell anaemia vaso-occlusive crisis as C-reactive protein. PLoS One. 2013;8(11):e77913.

14 Darbari DS, Sheehan VA, Ballas SK. The vasoocclusive pain crisis in sickle cell disease: definition, pathophysiology, and management. Eur J Haematol. 2020;105(3):237-46.

15 Lang RM, Badano LP, Mor-Avi V, Afilalo J, Armstrong A, Ernande L, et al. Recommendations for cardiac chamber quantification by echocardiography in adults: an update from the American Society of Echocardiography and the European Association of Cardiovascular Imaging. Eur Heart J Cardiovasc Imaging. 2015;16(3):233-70.

16 Khan SQ, Dhillon OS, O'Brien RJ, Struck J, Quinn PA, Morgenthaler NG, et al. C-terminal provasopressin (copeptin) as a novel and prognostic marker in acute myocardial infarction: Leicester Acute Myocardial Infarction Peptide (LAMP) study. Circulation. 2007;115(16):2103-10.

17 Ozmen C, Deveci OS, Tepe O, Yesildas C, Ünal İ, Yıldiz İ, et al. Prognostic performance of copeptin among patients with acute decompensated heart failure. Acta Cardiol. 2021;76(8):842-51.

18 Nickel NP, Lichtinghagen R, Golpon H, Olsson $\mathrm{KM}$, Brand $\mathrm{K}$, Welte $\mathrm{T}$, et al. Circulating levels of copeptin predict outcome in patients with pulmonary arterial hypertension. Respir Res. 2013;14:130.

19 Jiang L, Feng B, Gao D, Zhang Y. Plasma concentrations of copeptin, C-reactive protein and procalcitonin are positively correlated with APACHE II scores in patients with sepsis. J Int Med Res. 2015;43(2):188-95.
20 Ozmen C, Deveci OS, Karaaslan MB, Baydar O, Akray A, Deniz A, et al. Predictive value of plasma copeptin level for diagnosis and mortality of pulmonary embolism. Rev Assoc Med Bras (1992). 2020;66(12):1645-50.

21 Chalacheva P, Khaleel M, Sunwoo J, Shah P, Detterich JA, Kato RM, et al. Biophysical markers of the peripheral vasoconstriction response to pain in sickle cell disease. PLoS One. 2017;12(5):e0178353.

22 Mohammed FA, Mahdi N, Sater MA, Al-Ola $\mathrm{K}$, Almawi WY. The relation of C-reactive protein to vasoocclusive crisis in children with sickle cell disease. Blood Cells Mol Dis. 2010;45(4):293-6.

23 Mold C, Rodriguez W, Rodic-Polic B, Du Clos TW. C-reactive protein mediates protection from lipopolysaccharide through interactions with Fc gamma R. J Immunol. 2002; 169(12):7019-25.

24 Krishnan S, Setty Y, Betal SG, Vijender V, Rao $\mathrm{K}$, Dampier $\mathrm{C}$, et al. Increased levels of the inflammatory biomarker C-reactive protein at baseline are associated with childhood sickle cell vasocclusive crises. Br J Haematol. 2010;148(5):797-804.

25 Akohoue SA, Shankar S, Milne GL, Morrow J, Chen KY, Ajayi WU, et al. Energy expenditure, inflammation, and oxidative stress in steady-state adolescents with sickle cell anemia. Pediatr Res. 2007;61(2):233-8.

26 Adedeji MO, Cespedes J, Allen K, Subramony C, Hughson MD. Pulmonary thrombotic arteriopathy in patients with sickle cell disease. Arch Pathol Lab Med. 2001;125(11):1436-41.

27 Haque AK, Gokhale S, Rampy BA, Adegboyega P, Duarte A, Saldana MJ. Pulmonary hypertension in sickle cell hemoglobinopathy: a clinicopathologic study of 20 cases. Hum Pathol. 2002;33(10):1037-43.

28 Collins FS, Orringer EP. Pulmonary hypertension and cor pulmonale in the sickle hemoglobinopathies. Am J Med. 1982;73(6): 814-21.

29 Benedict CR, Johnstone DE, Weiner DH, Bourassa MG, Bittner V, Kay R, et al. Relation of neurohumoral activation to clinical variables and degree of ventricular dysfunction: a report from the Registry of Studies of Left Ventricular Dysfunction. SOLVD Investigators. J Am Coll Cardiol. 1994;23(6):1410-20. 